\title{
Amniotic band associated with human tail-like cutaneous appendage and spinal dermoid tumor: An
} exceedingly rare triad

\author{
Leopoldo Mandic Ferreira Furtado, M.D, MsC ${ }^{1}$ - José Aloysio da Costa Val Filho, MD, PhD ${ }^{1}$ \\ - Bruno Lacerda Sandes, MD ${ }^{1}$ - Gustavo Alberto Rodrigues da Costa, MD ${ }^{1}$ - Fernando Levi \\ Alencar Maciel, MD² - Eustaquio Claret dos Santos Júnior ${ }^{1}$
}

Received: 16 March 2020 / Published: 01 April 2020

\begin{abstract}
Introduction: The association between amniotic band syndrome (ABS) and spinal dysraphism is an extremely rare entity that was paucity reported in the literature so far and similar conditions such multiple asymmetric encephaloceles and anencephaly were also previously described with $A B S$.

Methods: In this case report, we described a male newborn in whom ABS was associated with human tail and lumbar dysraphism. A surgical approach was performed with intraoperative neurophysiological monitoring in which the tail and amniotic band were en bloc resected with favorable outcome. Dermoid tumor was identified by histopathological analysis

Conclusion: The occurrence of spinal dysraphism combined with ABS should be managed carefully in order to avoid spinal cord damage. provides very good results for a number of indications in children. Every effort should be made to optimize the selection of surgical candidates on the basis of their clinical features.
\end{abstract}

Key words: Amniotic band; Caudal appendage; Dermoid tumor; Spinal dysraphism

\section{Background}

Amniotic band syndrome (ABS) is a congenital malformation complex that occurs in association with amniotic bands and has a heterogeneous etiology, pathogenesis and clinical manifestations [1]. It can result in cutaneous scars, erosions and ulcerations, digital constricting bands, amputations, club feet, cleft lip, craniofacial and visceral anomalies [2, 3]. The incidence ranges from $1: 1,200$ to $1: 15,000$ live births [4-7].
Currently, three etiopathogenesis theories sought to explain $A B S$ : early amnion rupture, vascular

\footnotetext{
${ }^{1}$ Department of Pediatric Neurosurgery, Vila da Serra Hospital, Nova Lima, Minas Gerais, Brazil

${ }^{2}$ Faculty of Medicine, Federal University of Vale do Jequitinhonha and Mucuri, Minas Gerais, Brazil
}

To whom correspondence should be addressed: Leopoldo Mandic Ferreira Furtado, MD, MsC [e-

mail:Imandicster@gmail.com]

Journal homepage: www.sbnped.com.br

compromise, an early intrinsic defect of the developing embryo with polygenic inheritance. Most cases are sporadic with no recurrent risk $[1,8,9]$.

Although primary neurulation disorders such anencephaly have previously been correlated with amniotic band syndrome, there are only three descriptions of spinal dysraphisms associated with amniotic band and one case with human tail in the literature $[3,5,10,11]$. We analyzed the relationship between the appendage and the amniotic band from the clinicopathological findings of this patient.

\section{Clinical presentation}

A boy diagnosed with amniotic band at two trimester ultrasound was born by the cesarean delivery at 38 weeks. He has presented with APGAR 9 at five minutes. Weight of $2,100 \mathrm{~g}$ and height of 42 centimeters.

On examination was observed a high lumbar human tail connected with amniotic band (Figure 1). None other abnormalities were observed relative to 
amniotic band. A sterile curative was performed and he was
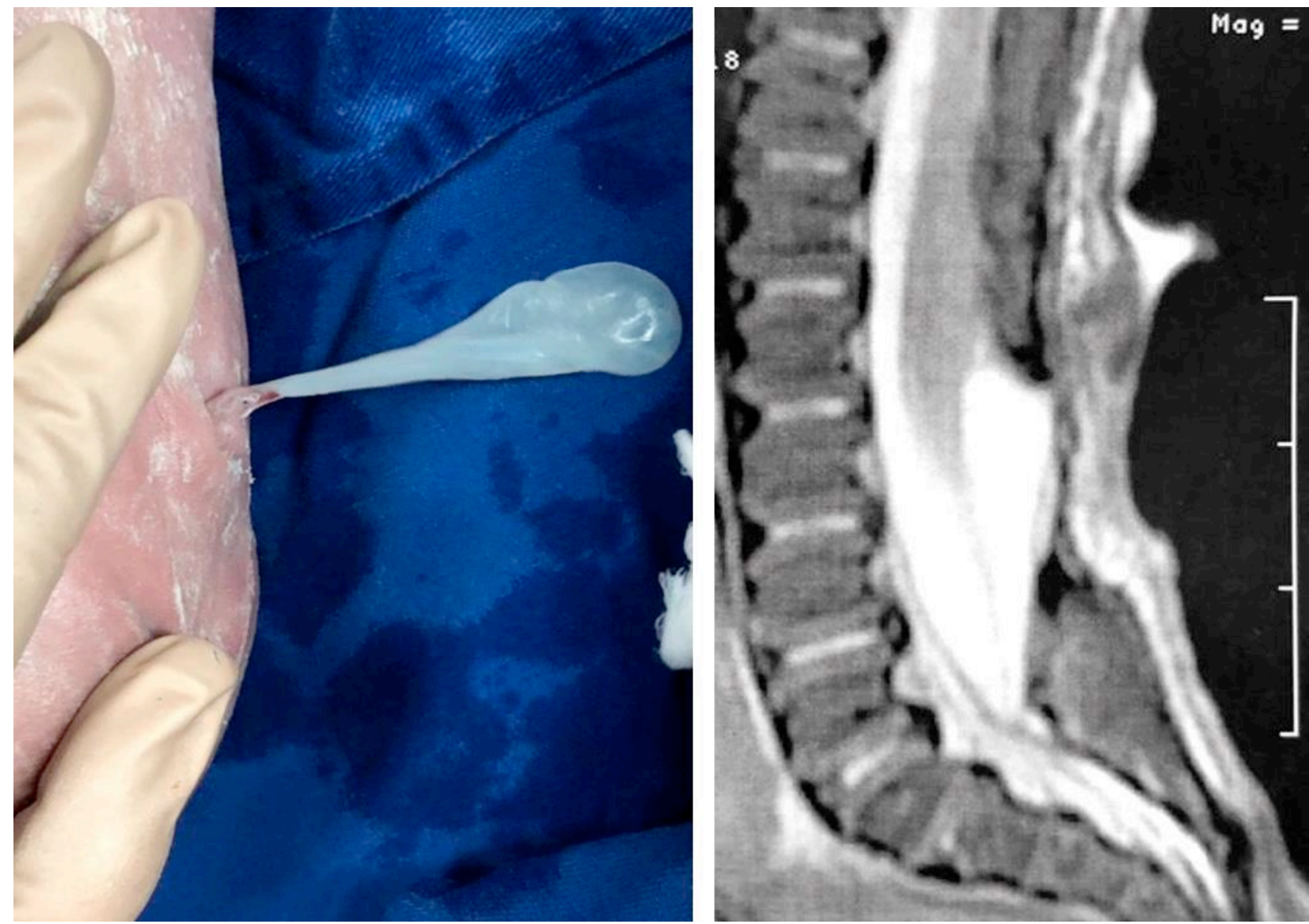

Figure 1 -Image of an amniotic band attached to lumbar human tail at born and a Lumbosacral midsagittal Magnetic resonance weight in T2 showing a Lumbar dysraphism.

transferred to intensive unit care in order to observe clinic parameters.

\section{Investigation}

How the human tail is a classic sign of occult dysraphism, we suggested a spinal investigation with magnetic resonance and it was accomplished in a second day. In which was observed a spinal dysraphism ranged to $L 2$ from $L 5$. Conus medullaris at L2 and human tail slightly above L2 (Figure 1).

Usually, when a baby was born with closed dysraphism, we do not operate until at least three months of age owing to relative risk of morbidity. However, in this case we choose for surgery approach to minimize the risk of central nervous system infection and provide the right diagnosis (Figure 2).

\section{Differential diagnosis}

Undoubtedly, the membranous shape of amniotic band attached to skin can be confused with meningocele. In this case, to the best of our knowledge the physical exam combined with magnetic resonance was paramount to rule out this condition (Figure 1).

Other congenital disorder such open spinal dysraphism can be excluded by cautious exam of skin. Moreover, myelomeningoceles usually present with neural tube open in a red placodium. However, in special presentations the myelomeningocele manquè should also be easily misdiagnosed with amniotic band.

Thus, meticulous physical examination of patient plus an information providing to obstetrician is meaningful in suspicion of this diagnosis.

\section{Treatment}

At five days of live, the operation was performed under general anesthesia and the latex free protocol was choose. In order to minimize neural injury, we adopt an intraoperative neurophysiological monitoring. The baby was positioned in a ventral decubitus and a skin was incised around human tail with Colorado needle tip electrocautery with a minimum blood loss. A microsurgical approach was accomplished resecting the extradural lesion, human 
tail and amniotic band tissue en bloc (Figure 2). The skin was closure with 3-0 Vycril and a Moncryl 4-0.
Hospital discharge has occurred at sixth day. The patient returned with fever and hemoculture
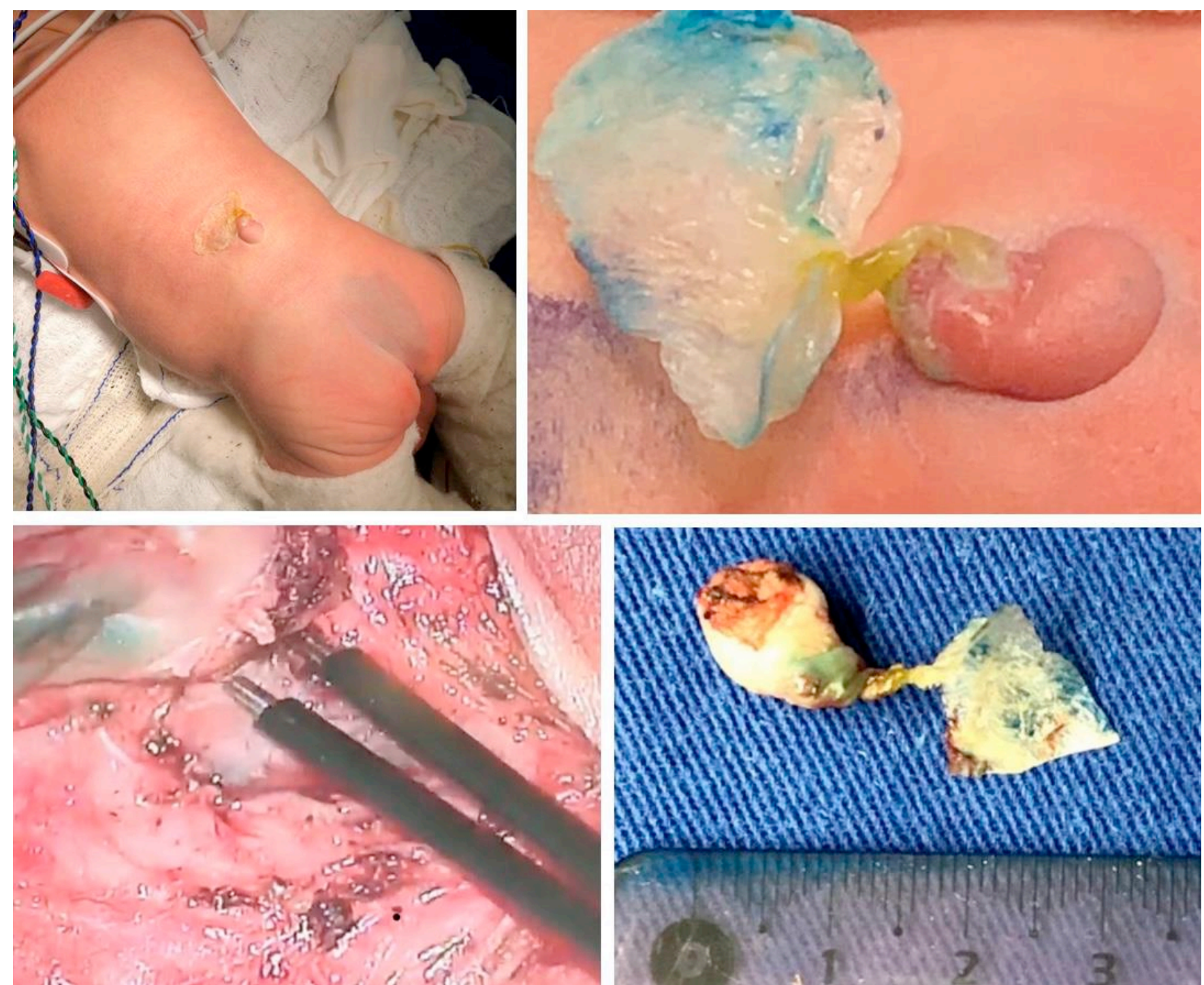

Figure 2 - Images of surgical approach of Amniotic band/Human tail en bloc resection demonstrating a position of appendage, electrode of neurophysiologic monitorization and after resection

positivation after seven day of hospital discharge. Received antibiotic therapy for twenty-one days without neurological or cicatrization problems and was discharged home from hospital.

\section{Outcome and follow-up}

At 6 months postoperatively, the boy presented uneventful cicatrization and a regular neurological examination.

Histopathological analysis was compatible with dermoid tumor and the amnion structure was confirmed in a tissue connected to a human tail (Figures 3 and 4).

\section{Discussion}

In this case report, we described a patient as having a human tail instead a pseudotail as considered by Sarukawa et al, $[12,13]$ in which paper have mentioned Dao and Netsky [14], and their classification for human tails in true tails and pseudotails. In this classification, true tails are vestigial remnants of embryonic human tails, whereas pseudotails are skin manifestations of underlying abnormal structures such as lipomas or teratomas. 


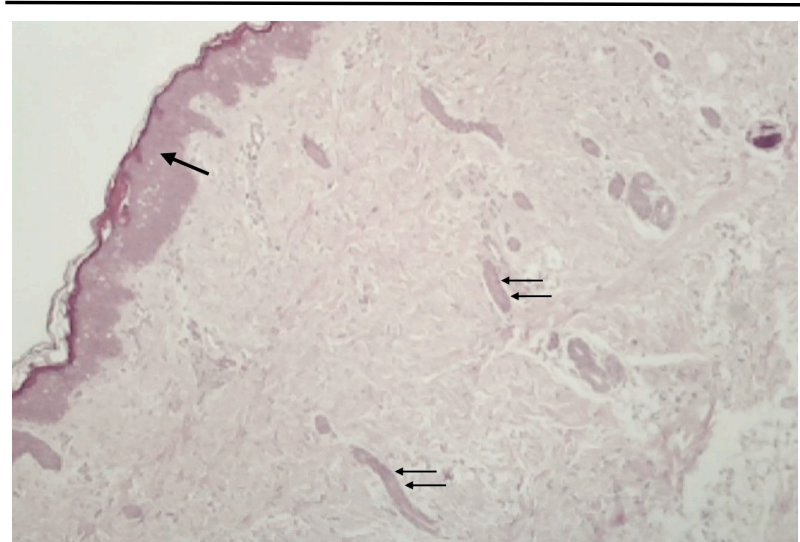

Figure 3 - Dermoid tumor demonstrating keratinized squamous stratified epithelium (Thick black arrow) and eccrine glands (double black arrows)

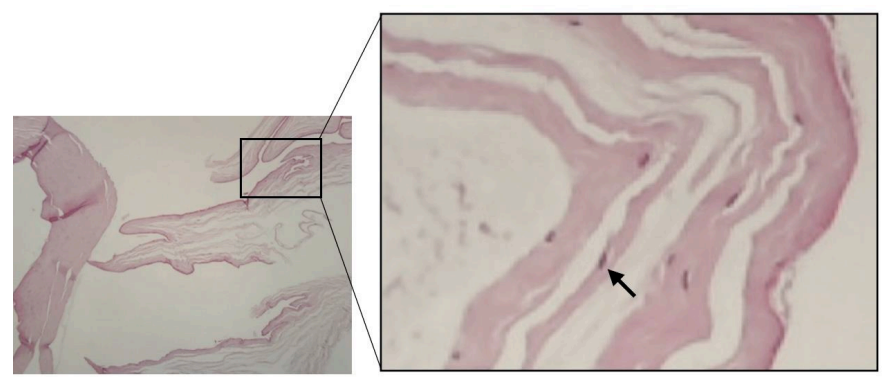

Figure 4 - Amniotic fragment represented by fibrous tissue containing fusiform cells without atypia (Black arrow in the magnification).

They stated that recent studies have made this system outdated and is accepted that tails are not remnants of the embryonic tails, but rather cutaneous markers for various spinal tethering lesions, including spinal lipomatous malformation, dermal sinus tracts, and split cord malformation. Indeed, we observed that in present case report the tail was the cutaneous stigma of lumbar dysraphism and a dermoid tumor.

Macroscopically, we observed that amnion band and human tail are very close and in order to avoid unnecessary bleeding and infection, was considered more safety the surgical approach by gentle dissection and in-bloc resection. This impression was confirmed by further microscopic analysis and this fact give light to pathophysiological hypothesis.

Interestingly, Prabhu and Tomita described the first case report of the association between ABS and tethering cord. They stated that the depth of penetration of amniotic bands could interfere in normal mesodermal migration between the neural and cutaneous ectoderm following disjunction, resulting in a dysraphic lesion and associated with tethering cord. Considered also that the neural tube closure was not affected, implying that the insult may have occurred around the fourth to fifth week of gestation when secondary neurulation was progressing [5].

Gkourogianni et al also reported a case of a boy born with ABS, human tail and a tethering cord by a spinal lipoma at L4-L5 level and has undergoing a surgical approach. They hypothesized that the triad of caudal appendage, amniotic band and, lipomyelocele is consistent with the association of myelocele with both ABS and tail deformity [11].

Therefore, human tail associated with amniotic band is an exceedingly rare occurrence and its management with a careful approach is paramount for a favorable outcome.

\section{Conflict of interest}

The authors report no conflict of interest concerning the materials or methods used in this study or the findings specified in this paper.

\section{References}

1.Barros M, Gorgal G, Machado AP, Ramalho C, Matias A, Montenegro N. Revisiting amniotic band sequence: a wide spectrum of manifestations. Fetal Diagn Ther. 2014;35(1):51-6.

2.Bourne $\mathrm{MH}$, Klassen RA. Congenital annular constricting bands: review of the literature and a case report. J Pediatr Orthop. 1987;7(2):218-21.

3.Pettorini B, Abbas N, Magdum S. Amniotic band syndrome with tethering of the spinal cord: a casebased update. Childs Nerv Syst. 2011;27(2):211-4.

4.Quintero RA, Morales WJ, Phillips J, Kalter CS, Angel JL. In utero lysis of amniotic bands. Ultrasound Obstet Gynecol. 1997;10(5):316-20.

5.Prabhu VC, Tomita T. Spinal cord tethering associated with amniotic band syndrome. Pediatr Neurosurg. 1999;31(4):177-82.

6.Seeds JW, Cefalo RC, Herbert WN. Amniotic band syndrome. Am J Obstet Gynecol. 1982;144(3):243-8.

7. Galvan A, Alvarez E, Parraguirre S, Suarez ML, Perez A. Development of a fetal rabbit model to study amniotic band syndrome. Fetal Pediatr Pathol. 2012;31(5):300-8.

8.Torpin R. Amniochorionic Mesoblastic Fibrous Strings and Amnionic Bands: Associated Constricting Fetal Malformations or Fetal Death. Am J Obstet Gynecol. 1965;91:65-75.

9.Van Allen MI, Curry C, Gallagher L. Limb body wall complex: I. Pathogenesis. Am J Med Genet. 1987;28(3):529-48.

10.Cincore V, Ninios AP, Pavlik J, Hsu CD. Prenatal diagnosis of acrania associated with amniotic band syndrome. Obstet Gynecol. 2003;102(5 Pt 2):1176-8. 11.Gkourogianni A, Dermentzoglou V, Skiathitou AV, Tsina E, Giannakopoulou C, Siahanidou T. Human tail: a rare feature of amniotic band syndrome? Clin Dysmorphol. 2016;25(1):41-3.

12.Sarukawa M, Morioka T, Murakami N, Shimogawa T, Mukae N, Kuga N, et al. Human tail-like cutaneous appendage with a contiguous stalk of limited dorsal myeloschisis. Childs Nerv Syst. 2019;35(6):973-8.

13.Sarukawa M, Morioka T, Murakami N, Shimogawa T, Mukae N, Kuga N, et al. Correction to: Human taillike cutaneous appendage with a contiguous stalk of limited dorsal myeloschisis. Childs Nerv Syst. 2019;35(6):1091.

14.Dao AH, Netsky MG. Human tails and pseudotails. Hum Pathol. 1984;15(5):449-53 